UDK: $336.748 .12(540)$

DOI: 10.2478/jcbtp-2020-0042
Journal of Central Banking Theory and Practice, 2020, 3, pp. 163-182

Received: 19 March 2019; accepted: 27 June 2019
Jithin P*, Suresh Babu M ${ }^{* *}$

\section{Testing for the Effectiveness of Inflation Targeting in India: A Factor Augmented Vector Autoregression (FAVAR) Approach}

\begin{abstract}
Employing Factor Augmented Vector Autoregression (FAVAR) model where factors are obtained using the principal component analysis (PCA) and the parameters of the model are estimated using Vector Autoregression framework, we analyse how changes in monetary policy variables impact inflation, output, money supply, and the financial sector in India. Our results for the period 2001:04 to 2016:03 show that the benchmark FAVAR model showed more reliable results than baseline VAR model. Benchmark FAVAR model shows the existence of weak 'liquidity puzzle' in India. The impulse responses from the FAVAR approach reveal that monetary policy is more efficient in explaining the variations in inflation rather than stimulating output indicating its effectiveness in attaining the objective of price stability.
\end{abstract}

Keywords: Factor Augmented VAR, Monetary policy, Economic growth, Inflation.

JEL classification: C32; E52; O47; E3

\section{Introduction}

The effectiveness of monetary policy in combating inflation has always been an important question in emerging economies, including India, as inflationary pressures have augmented recently. IMF (2012) provides a demand-side
${ }^{*}$ Department of Humanities and Social Sciences, Indian Institute of Technology Madras, Chennai, India

Email (Corresponding author): jithinpchand21@gmail.com

${ }^{* *}$ Department of Humanities and Social Sciences, Indian Institute of Technology Madras, Chennai, India

Email: 
explanation for the growing inflationary pressure in emerging market economies. Given the fluctuations in global economic environment, the IMF's argument can be viewed only as one of the plausible explanations for the rising inflationary pressure in economies such as India. As a major importer of petroleum products the role of supply factors is also equally important for India. Further, the changes in commodity prices in international markets too would affect the domestic prices. Therefore, the booms and busts in international commodity prices cannot be neglected while analysing inflation in India. Given the backdrop there is a consensus that monetary tightening has failed in delivering its desired impact on curtailing inflation. The "baby steps" approach of monetary policy is considered as the main reason for the persistence of inflation and it is often claimed that there is a trade-off between the objectives of monetary policy such as price stability and stimulating economic growth. The aggressive tightening in the early stages of inflation leads to the slowdown in economic growth but it will stabilize the inflation being part of the trade-off ${ }^{1}$.

While there are different empirical approaches to investigate the implications of monetary policy on an economy in terms of its objectives such as price stability and economic growth. Vector Autoregressions (VARs) is considered as a globally accepted framework to examine the effectiveness of monetary policy shocks on macroeconomic activity (Primiceri 2005; Boivin and Giannoni 2006; Saxegard 2006; Gambacorta, Hofmann \& Peersman, 2014). An important limitation of the standard VAR approach is that it addresses only unanticipated changes in monetary policy and it employs a relatively less information about economic activities to maintain degrees of freedom. An illustration of the problem that we are dealing in this paper is discussed in Sims (1992), which provides an interpretation of the "price puzzle". A common result using the conventional VAR is that a contractionary monetary policy in turn leads to a small increase in the price level instead of the theoretical argument of decreasing price level; therefore, it is contrary to the theoretical argument. Sims explained this phenomenon as the aftereffects of asymmetric information or imperfectly controlling for information of the central bank about the future. For overcoming this problem Bernanke and Boivin (2003) and Bernanke, Bolivin, \& Eliasz (2005) extended the VAR model by incorporating a larger number of information using factor analysis to evaluate the implications of monetary policy on economic activity in a data rich environment. They extended the VAR methodology by adding the common factors into standard VAR model specification. Based on the pioneering works of Ber-

\footnotetext{
1 In a note entitled "Baby Steps toward Normalization," Bank of America Merrill Lynch (2017) argued that "if it were solely about the data, the European Central Bank would probably do little more than acknowledge that risks to the economic outlook have turned neutral from negative".
} 
nanke and Boivin and Bernanke, Bolivin, \& Eliasz, many studies using FAVAR approach have been conducted in different country contexts ${ }^{2}$.

While the literature is diverse on impacts of monetary policy on inflation and economic growth, the relevance of this paper stems from the fact that recent research shows that the larger number information about the macroeconomic variables can be summarized into small number of factors. For instance, Stock and Watson (2002) constructed an approximate dynamic factor model by employing data from large data sets for forecasting purposes. They find that forecasting and estimation based on the factor analysis provides more precise estimates than the standard VAR estimations. Bernanke and Boivin (2003) find that the estimated factors can provide more reliable results in the estimation of the impacts of Fed's policy reaction function. Given these empirical developments, this paper seeks to examine the impacts of monetary policy on macroeconomic activity (output, prices and money) in India using the FAVAR methodology proposed by Bernanke, Bolivin, \& Eliasz (2005), as such an attempt is conspicuously absent in the Indian context.

The paper is organized into six sections. Section 2 provides a review of the existing literature, which deals with the impacts of monetary policy on price stability and economic growth. Section 3 deals with the trends in monetary policy and macroeconomic variables in India. Section 4 describes data sources and methodology. Section 5 presents results and section 6 concludes the paper.

\section{Impact of Monetary Policy: Evidence in the Indian Context}

The existing literature on the effects of monetary policy on macroeconomic variables shows that it has been diverse across economies, depending on countryspecific characteristics. Price stability is considered as an important objective of monetary policy since changes in price levels leads to uncertainty in an economy in terms of decision-making and the increase in prices negatively affects savings and leads to increase in speculative activities in the economy. In the case of emerging economies, Aguir (2018) finds that the transparency, independence and credibility of central banks is essential for emerging economies to face a decline in inflation following the adoption of inflation targeting. Awdeh (2019) finds that the monetary policy has negative and significant impacts on economic growth which implies that monetary policy depresses the output in the long run.

2 Lahura (2010) for Peru, Figueiredo (2010) and Junior (2009) for Brazil, He et al. (2013 for China, Munir and Qayyum (2012) for Pakistan, and Ribon (2011) for Israel are some examples. 
At the same time, monetary policy transmission channels through bank credit and capital play a vital role in GDP growth. Twinoburyo and Odhiambo (2018) show that monetary policy really matters for growth both in the short run and the long run. They recommend developing countries to develop their financial markets to address the supply side deficiencies.

In the Indian context, some of the existing literature (Upadhyaya, 1991; Reddy, 2004) supports the monetary view that monetary policy plays a vital role in economic activity. Rangarajan (1997) find that the moderation of monetary growth is needed since it can affect the objectives of economic growth through inflation if it goes beyond 6\%. Ramachandran and Kamaiah (1994) find that monetary policy is effective in attaining the objective of price stability than inducing economic growth. There are differing views on the impacts of monetary policy on macroeconomic variables and there is a continuing debate about these. The major themes in the debate include instruments, objectives and the impacts of monetary policy. Monetary management in the 1980s and especially in the 1990s in India provides some interesting insights about the major role played by the monetary policy in stabilising economy and acting as an instrument for economic policy. Rangarajan et al (2001) state some important lessons based on this background. They suggest that assigning the instruments for appropriate objectives leads to help in achieving the objective of price stability. This in turn leads to the era of a single objective approach. Vasudevan (2002) argues that the Reserve Bank of India (RBI) adopted the "Just do it" approach rather than any rule based regime. Cautious adopting of this approach is not because of a policy procedure but due to uncertainties in the market behaviour and development in the context of financial development.

Kannan, Sanyal \& Bhoi (2006) constructed a monetary conditions index (MCI) for India for evaluating the monetary conditions and the impacts of monetary policy on economic activity by incorporating both the exchange rate and interest rate channels. They find that interest rate is a crucial factor in influencing monetary conditions in India rather than the exchange rate. Bhattacharyya and Sensarma (2005) also developed a measure of monetary policy stance and using this constructed measure they find that the monetary policy is more effective in stabilising the price level $v i s-\grave{a}$-vis inducing output. Bhattacharyya and Sensarma (2008) find that quantity adjustments through cash reserve ratio (CRR) have significant impacts on the financial market even though the RBI identified the bank rate as the principal signalling instrument. They also find that the impact of signalling instrument on stock market is insignificant and it is confined to the foreign exchange, bond markets, and money. Bicchal (2010) finds that the results are tandem with the theoretical expectation that call money rate shocks were con- 
sistent with the prediction. The results show a good approximation of the existing monetary dynamics of the RBI. He also finds that monetary policy transmission were more effective for wholesale prices rather than core prices, at the same time interest rate channel is more stronger for core prices. Ramachandran and Kumar (2017) show that the response of inflation to the supply as well as demand shocks is very high in times of Eurozone crises and the global financial crisis that happened from 2007 to 2012. It helps to understand the inflation dynamics in India.

The above mentioned studies consider only a limited set of variables, thereby capturing only limited information to examine the impact of monetary policy on macroeconomic variables. The FAVAR proposed by Bernanke, Bolivin, \& Eliasz (2005) incorporated the larger number of information in the standard VAR model by including latent dynamic factors in the analysis and the observed variable is represented by the federal fund rate. Mordi et al. (2013) employ the FAVAR methodology to analyse the reaction of different prices (the components of the Consumer Price Index (CPI)) to interest rate and exchange rate shocks and identify the factors that determine direction and extent of responses in Nigeria. Their findings reveal that a shock to the monetary policy rate has a mixed effect on the CPI components as well as all CPI items. In general, the existence of a "price puzzle" is observed, however, most of the CPI components of decline in response to unanticipated shocks to monetary policy rate with the effect on housing water, electricity, gas and other components being the most significant.

Belviso and Milani (2006) extend the factor augmented VAR to structural factor augmented VAR (SFAVAR) model using Bayesian approach to extract the factors from large data sets. They incorporated the factors like inflation factor, financial market factor, real activity factor, expectation factor, and credit factor in the SFAVAR methodology. Rosoiu (2015) argues that the introduction of the FAVAR methodology in the econometrics literature will help the researchers to solve so many problems in the estimation of the impacts of monetary policy transmission on economic variables. He finds that unemployment rate is more sensitive to the number of factors rather than the inflation rate.

Given this backdrop, we adopt the FAVAR approach to empirically analyse the effectiveness of monetary policy in attaining the objectives of price stability and economic growth in India in the post-reform period. This adds to the literature on the effectiveness of monetary policy in India, as the notable existing studies (Ramachandran and Kamaiah 1994; Rajan and Yanamandra, 2015) have not used factor analysis to measure the effects of monetary policy in a data-rich environment. 


\section{Trends in Monetary Policy in India (2001-2016)}

Last three decades have witnessed a rapid growth in the money supply in India. India is an emerging economy with a higher population rate, therefore, the demand for credit from private sector increases tremendously. Reserve Bank of India targets monetary aggregates (M3) in order to achieve the objective of economic growth and price stability. In order to achieve the objectives, the RBI is using the following instruments such as (a) Repo and Reserve Repo rate; (b) cash reserve requirements (CRR), and (c) statutory liquidity ratio (SLR).

Figure 1: Inflation and growth rate of M3

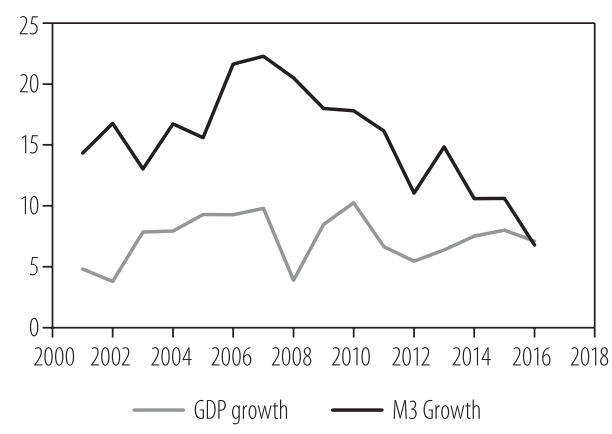

Source: Reserve Bank of India
Figure 2: Growth rate of GDP and M3

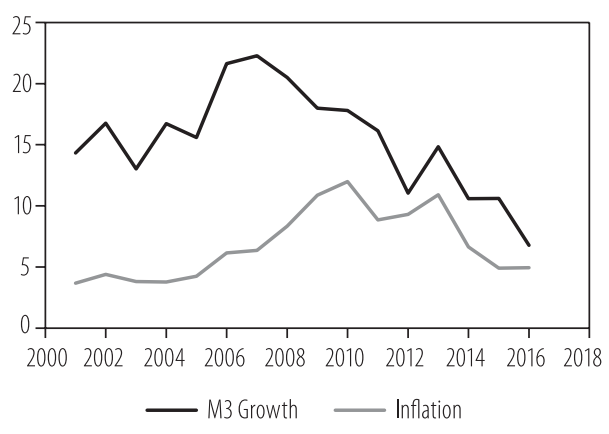

Source: Reserve Bank of India

The Reserve Bank of India tried to dampen the inflationary pressures in the last few years but rarely refers to money aggregates in its policy statements. Figure 1 shows the trends in inflation rate and money supply growth (M3 Growth rate) (2001-2016), while Fig. 2 shows the trends in the growth rate of GDP and growth rate of M3 (2001-2016). The effectiveness of monetary policy has always been an important question in India, as inflationary pressures have augmented recently.

\section{Data and Methodology}

\subsection{The model}

Following Bernanke and Boivin (2003), we employ the FAVAR method for analysing the effectiveness of monetary policy. Let $Y_{t}$ be a Mx1 vector of observable economic variable assumed to have prevalent effects throughout the economy. If we follow the traditional approach then we will end up with estimating the VAR, 
a structural VAR (SVAR) or other multivariate time series estimations using the Y variable data alone. However, the traditional approach does not capture the full information about the variable and large additional information is missing. We use the FAVAR approach to improve the estimation of the impacts of monetary policy through the usage of richer additional information. To specify the factor augmented vector auto regression, the relationship between $\mathrm{Y}_{\mathrm{t}}$ and $\mathrm{F}_{\mathrm{t}}$ is expressed as follows:

$$
\begin{aligned}
& {\left[\begin{array}{c}
X_{t}^{1} \\
X_{t}^{2} \\
\cdots \\
X_{t}^{I}
\end{array}\right]=\left[\begin{array}{cccc}
\Lambda_{1}^{f} & 0 & \cdots & 0 \\
0 & \Lambda_{2}^{f} & \cdots & 0 \\
\cdots & \cdots & \cdots & \cdots \\
0 & 0 & \cdots & \Lambda_{I}^{f}
\end{array}\right] \cdot\left[\begin{array}{c}
F_{t}^{1} \\
F_{t}^{2} \\
\cdots \\
F_{t}^{I}
\end{array}\right]+e_{t}} \\
& {\left[\begin{array}{l}
F_{t} \\
Y_{t}
\end{array}\right]=\Phi(L)\left[\begin{array}{c}
F_{t-1} \\
Y_{t-1}
\end{array}\right]+v_{t}}
\end{aligned}
$$

where $\Lambda^{\mathrm{f}}, \Lambda^{\mathrm{y}}$ is factor loadings of $\mathrm{N} \times \mathrm{K}$ and $\mathrm{N} \times \mathrm{K}$ dimensions that conform to $\mathrm{X}_{\mathrm{t}}$, $F_{t}$, and $\mathrm{Y}_{\mathrm{t}}$. The error terms $\mathrm{e}_{\mathrm{t}}$ is $\mathrm{N} \times 1$ vector, the mean is zero and the correlation of error term depends on the estimation of FAVAR. Error term assumes uncorrelated or weakly correlated based on the estimation method is either by likelihood methods or by principal component analysis. The mean and covariance of the error term are zero and matrix Q. Where the $\Phi$ is a conformable lag polynomial of finite order $\mathrm{d}$ and it may have a priori restrictions as in the SVAR literature.

We cannot estimate the above equation directly since the factors $F_{t}$ are unobservable. We take the factors as explanatory variables and this will help better interpret the economic variables. The number of observations $\mathrm{N}$ is "large" and it should be greater than the number of factors.

We assume that informational time series $\mathrm{X}_{\mathrm{t}}$ are related to the observable factor $\mathrm{Y}_{\mathrm{t}}$ and the unobservable factor $\mathrm{F}_{\mathrm{t}}$.

$$
X_{t}^{\prime}=\Lambda^{f} F_{t}^{\prime}+\Lambda^{y} Y_{t}^{\prime}+e_{t}^{\prime}
$$

The above equation shows the correlation between $\mathrm{Y}_{t}$ and $\mathrm{F}_{\mathrm{t}}$ which represent the pervasive forces which determine the dynamics of $X_{t}$. Conditional on the $Y_{t}$, the $\mathrm{X}_{\mathrm{t}}$ are thus noisy measures of the underlying unobserved factors $\mathrm{F}_{\mathrm{t}}$. The equation implies that $\mathrm{X}_{\mathrm{t}}$ depends up on the present values of the factors not the lagged values. Following Stock and Watson (2002) we can refer to the equation (3) without observable factors as a dynamic factor model. 


\subsubsection{Identification of the factors}

The analysis starts with the estimation of common components $\mathrm{C}_{t}$ using the first $\mathrm{K}+\mathrm{M}$ principal components of $\mathrm{X}_{\mathrm{t}}$. The principal component analysis does not incorporate the fact that $\mathrm{Y}_{\mathrm{t}}$ is observed. However, $\widehat{F}_{t}$ is obtained as the part of the space covered by $\mathrm{C}_{\mathrm{t}}$, which is not covered by $\mathrm{Y}_{\mathrm{t}}$. Secondly, the FAVAR equation (2) is estimated using ordinary least squares (OLS), $F_{t}$ replaced by $\widehat{F}_{t}$. We have used the Repo rate as the monetary policy instrument for our analysis. Thus, the innovation in Repo rate is the monetary policy shocks. Based on Bernanke, Bolivin, \& Eliasz (2005) we used repo rate (monetary policy instrument, i.e., $\mathrm{R}_{\mathrm{t}}$ ) as observable (only variable in the vector $Y_{t}$, i.e., $Y_{t}=R_{t}$ ), and the rest of the variables are unobservable. We have followed the recursive procedure to determine the monetary policy shocks, all the factors entering Eq. (2) reacts with a lag to change in monetary policy instrument in our case repo, which is ordered last in the FAVAR.

The equation (2) or the FAVAR can be estimated only after estimating the unobservable factors using the principal component analysis. This study follows the Bernanke, Bolivin, \& Eliasz (2005) approach to estimate the FAVAR model. The informational time series $X_{t}$ is segregated into fast and slow moving variables. The fast moving variables are the economic variables, which are highly sensitive to the monetary policy shocks such as financial assets and prices. Slow moving variables are those which are not sensitive to the contemporaneous policy shocks, or they are predetermined as, for instance, real variables. The classification of fast moving and slow moving variables in our estimation is explained in the Appendix. We use the principal component method to estimate the Common factors $\mathrm{C}_{t}$ on all variables included in $\mathrm{X}_{t}$ and we use slow moving variables to estimate slow moving factors $\mathrm{F}_{s t^{\circ}}$. Then the common components $\mathrm{C}_{t}$ are regressed on the estimated slow-moving factors and on the observed policy factor (repo rate).

\subsubsection{Identification of the VAR}

We assume a recursive structure to identify the macroeconomic shock, unanticipated changes in the monetary policy instrument that is repo rate. For estimating the residuals, the Cholesky decomposition of the variance-covariance matrix, which is a simple algorithm for splitting a symmetric positive definite matrix into a lower triangular matrix multiplied by its transpose, is used in recursiveness assumption. Our analysis follows the Cholesky Decomposition scheme in which the policy variable, i.e. Repo rate, is ordered last and treats its innovations as the policy shocks. The existing literature on multivariate time series analysis recommends several criteria for determining the number of factors, large section of the 
empirical studies used the Bai and $\mathrm{Ng}$ (2002) method of factor extraction. However, there are no criteria for the number of factors included in the model and the restrictions are imposed to conserve degrees of freedom. We estimated the FAVAR model with five factors ( $\mathrm{K}=5)$, VAR model with three factors $(\mathrm{K}=3)$, VAR model with one factor $(\mathrm{K}=1)$. The results are robust to the use of more than five factors. Therefore, the FAVAR model with five factors is our benchmark model. We employed the likelihood ratio (LR) test to finding out the lag structure of the VAR and FAVAR models, so to include 12 lag is appropriate to overcome the problem of serious autocorrelation.

\subsection{Data Transformation}

We use 59 monthly macroeconomic indicators of India to estimate the factors for our analysis. These were chosen mainly from six categories: output, money, prices, stock prices, interest rate, and exchange rates. The data sources include the Reserve Bank of India, International financial statistics, and Indiastat.com. The data span is April 2001 to March 2016. There are many data limitations which we need to consider before proceeding further. GDP is available as a quarterly frequency data, so we used the index of Industrial Production as a proxy for GDP and which is available on monthly basis. The Appendix lists all the data series included in the dataset.

Before estimating the FAVAR the data have been processed in four stages. First, seasonal adjustment of data since some of our variables exhibit periodic fluctuations and seasonal variations, which leads to the changes in the characteristics of the data. For tackling this issue, we adjusted the data using the multiplicative decomposition of the census X13 process in EVIEWS. The Appendix (see the Appendix below) describes whether a series is seasonally adjusted or not. Secondly, we use the logarithmic transformation to achieve linearity of the data since it is important in dealing with the macroeconomic time series which shows exponential growth. Therefore, logarithmic transformation is a suitable way to transform the series. The transformation of individual series is described in the Appendix. Thirdly, as mentioned earlier, all the variables included in $\mathrm{X}_{\mathrm{t}}$ should be stationary. We employ KPSS, Augmented Dicky Fuller (ADF) tests to check the stationarity of data. Finally, all the macroeconomic time series are on different scale and units, which can weaken our factor extraction for the analysis. To tackle this issue, all the informational time series are standardised to have a unit variance and mean zero. 


\section{Results and Discussions}

The FAVAR model which we specify in eq (2) will become a standard VAR model if we assume that all $\Phi(\mathrm{L})=0$ in Eq. (2) which relates Yt to Ft . Our basic baseline VAR is four dimensional VAR of inflation, money, industrial production, and repo rate in Choleski ordering. Concurrently, the benchmark FAVAR model comprises policy variable (repo rate), five factors, and variables of interest. To check the reliability of results we compare the baseline VAR model and benchmark FAVAR model and then add one and three factors in the baseline model to check whether the inclusion of more factors improves the results of VAR models or not. The models used for the estimations and comparison are as follows:

i) Benchmark FAVAR model ( $\mathrm{Y}=\mathrm{Repo}$ and $\mathrm{K}=5$ )

ii) Baseline VAR model ( $\mathrm{Y}=\mathrm{IIP}, \mathrm{M} 3$, WPI, Repo and $\mathrm{K}=0$ )

iii) VAR model with one factor (Y=IIP, M3, WPI, Repo and $\mathrm{K}=1$ )

iv) VAR model with three factor (Y=IIP, M3, WPI, Repo and K=3)

Figures 3, 4, 5, and 6 show the impulse response functions of baseline VAR model, alternative baseline VAR models with one factor and three factors, and benchmark FAVAR model. We use 25 basis point positive shocks to the repo rate to examine the response of IIP, WPI, M3 and Repo. Figure 3 portrays the impulse response function of a 25bp positive shock on Repo rate on Repo rate. As it can be seen in the baseline VAR model the Repo rate reflects its own shock and converges to zero after 10 months. When we include the factors to the baseline VAR model our results are improved and the benchmark FAVAR model is much more consistent as the repo rate reflects its own shocks and converges to zero after 26 months, which is consistent with theory. 
Figure 3: Impulse response of a $25 \mathrm{bp}$ shock in Repo rate on Repo rate

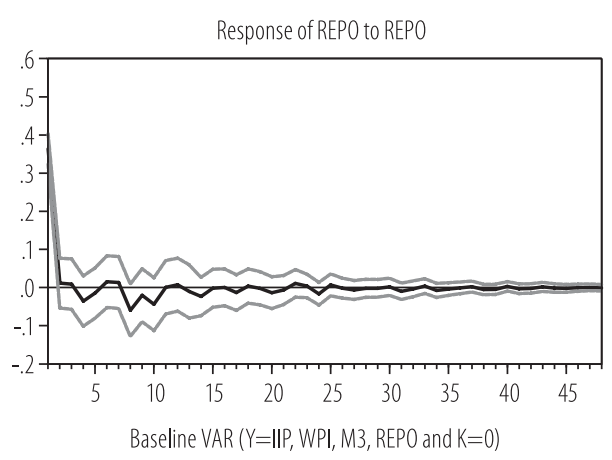

repo

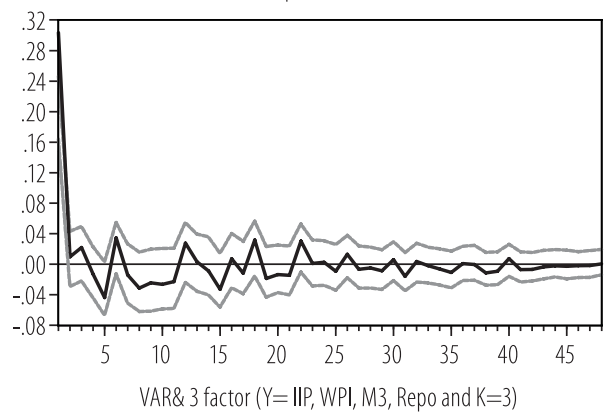

repo

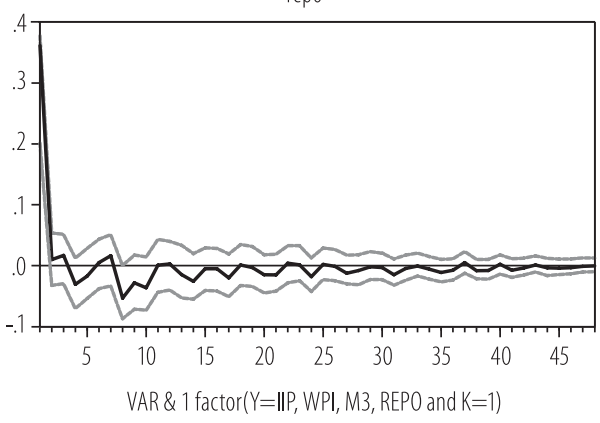

repo

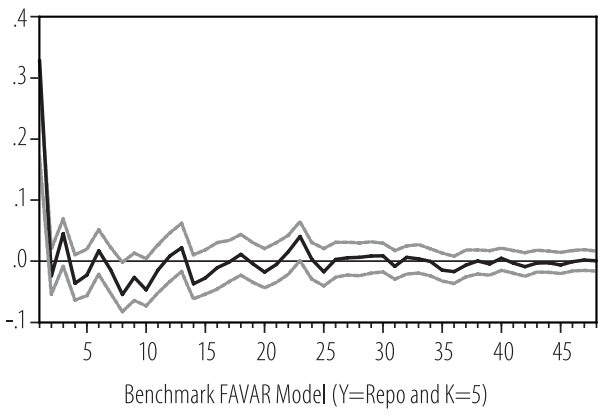

Figure 4 presents the impulse response function of a 25bp positive shock in Repo rate on WPI. The benchmark FAVAR model shows that after a 25bp shock, the WPI initially shows a meagre increase and starts decreasing thereby reaching a minimum in the fourth month. At the same time, the baseline VAR model shows that WPI is unaffected initially by the positive shock in repo rate and after second month it decreases and reaches a minimum in the $9^{\text {th }}$ month, showing a reviving trend and convergence in the $42^{\text {nd }}$ period. The result shows no sign of price puzzle in India. The estimation results of the benchmark FAVAR model are in line with the theoretical expectation that a positive shock in monetary policy leads to decrease in prices. The result also shows that the impact of monetary policy shocks has faster contemporaneous effects on prices as compared to output. 
Figure 4: Impulse response of a $25 \mathrm{bp}$ shock in Repo rate on Wholesale price index
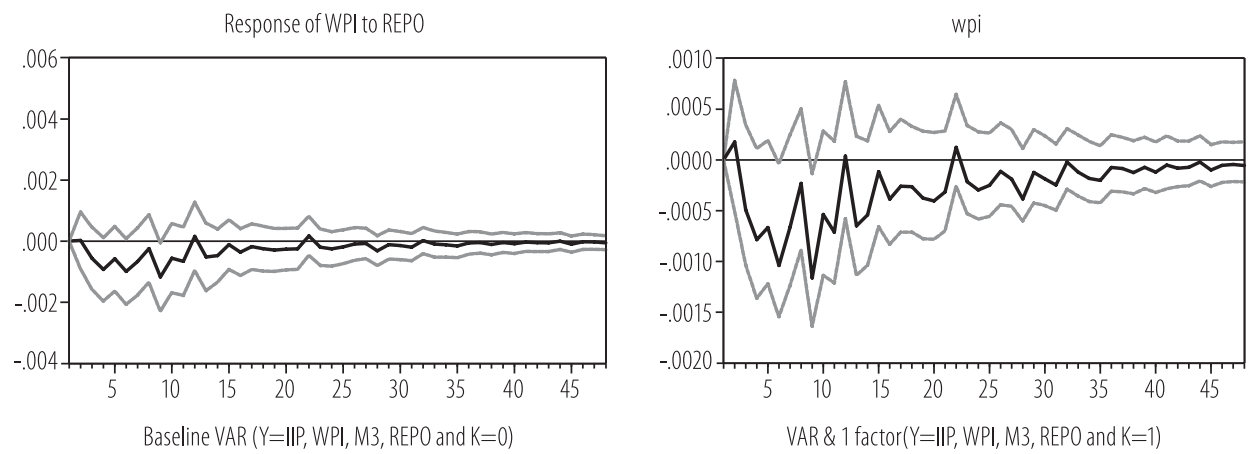

wpi
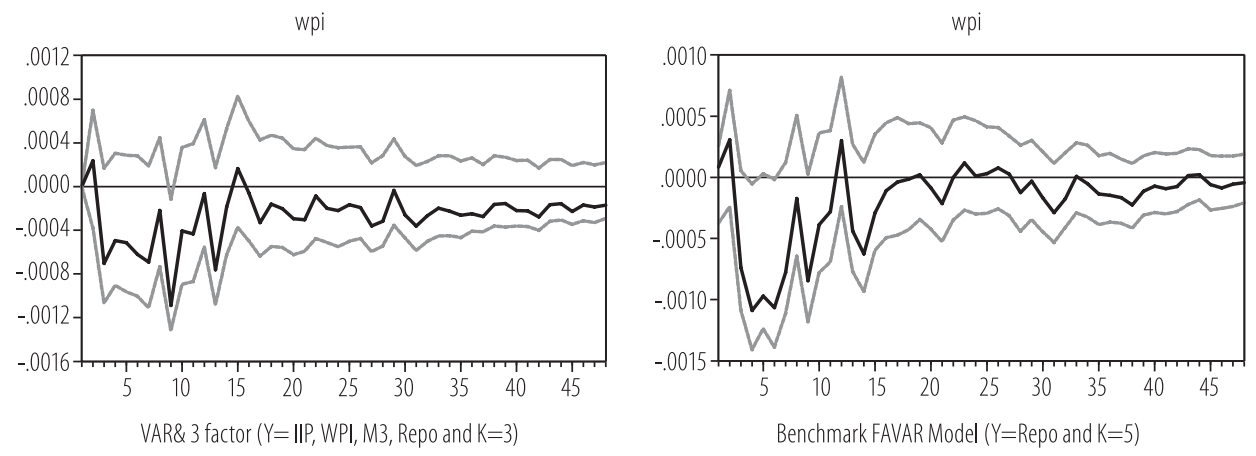

Figure 5 shows the impulse response function of a 25bp positive shock in Repo rate on the index of industrial production (IIP). In the benchmark FAVAR model, after the shock, the IIP shows increasing trend and after 3 months it starts decreasing and converges to zero after 40 months. At the same time baseline VAR model shows an opposing result. In the initial period, the IIP shows decreasing trend and after three months it starts increasing. On an average, our results indicate the non-neutrality of money in the long run. Nonetheless, the results of the benchmark FAVAR model is in tandem with the existing theory since it shows the long run neutrality of money in India which implies that the monetary policy variable does not have any significant effects on the IIP (real economic activity) in the long run. 
Figure 5: Impulse response of a $25 \mathrm{bp}$ shock in Repo rate on index of industrial production
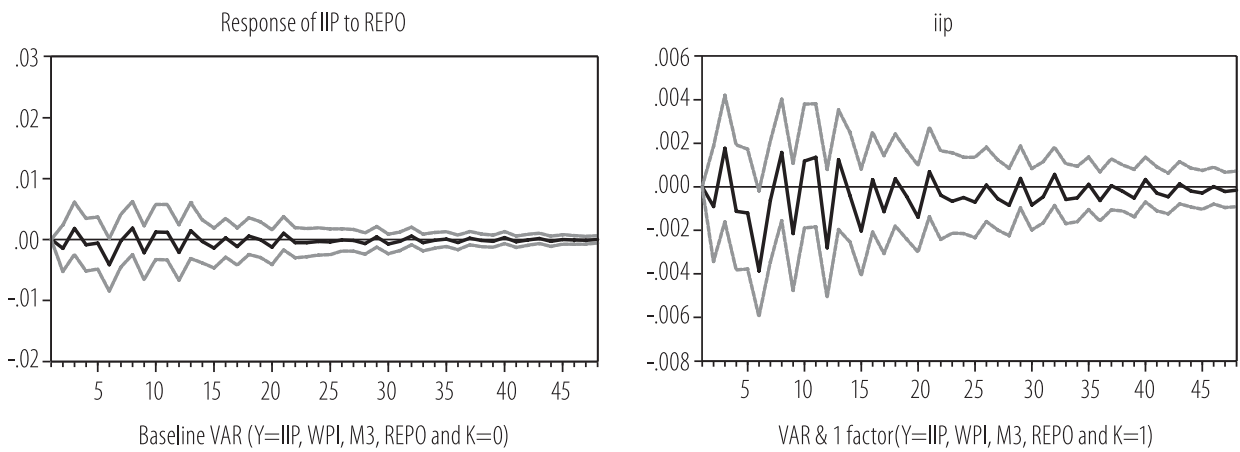

iip
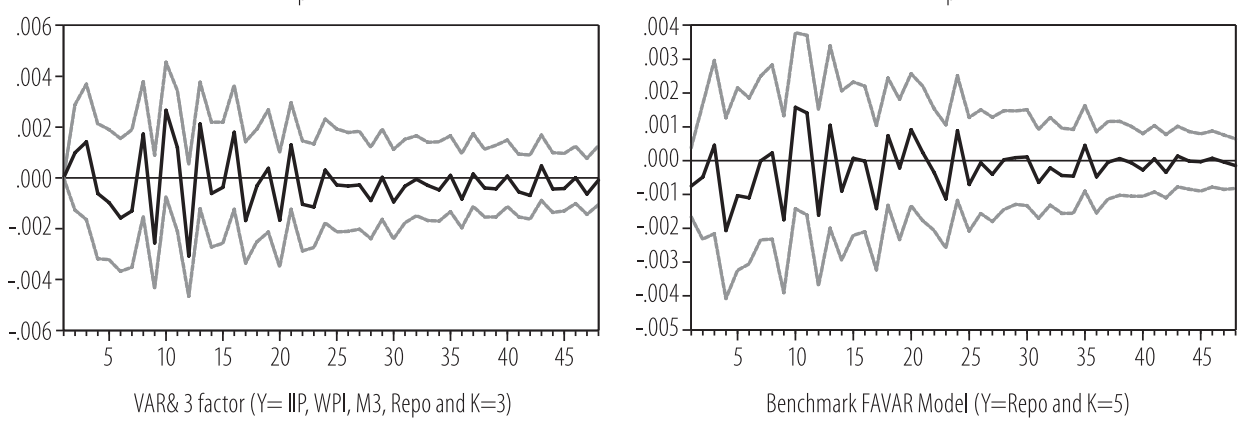

Figure 6 shows the impulse response function of a 25bp positive shock in Repo rate on money supply (M3). The benchmark FAVAR model shows that money supply is not changing significantly in the initial period or is largely unaffected by the positive shock in Repo rate; after three months, it increased and remained persistent up to 40 months. This finding is inconsistent with the conventional theory of transmission that an increase in interest rate leads to a decrease in money supply. Moreover, this finding is consistent with the liquidity puzzle which means that increase in interest rate causes the money supply to increase. The baseline VAR model results are improving when we are including factors. It shows that after shock, money supply increases and reaches maximum in the $3^{\text {rd }}$ period and converges to zero in the $5^{\text {th }}$ period. The benchmark FAVAR indicates the existence of weak liquidity puzzle in India. 
Figure 6: Impulse response of a $25 \mathrm{bp}$ shock in Repo rate on M3

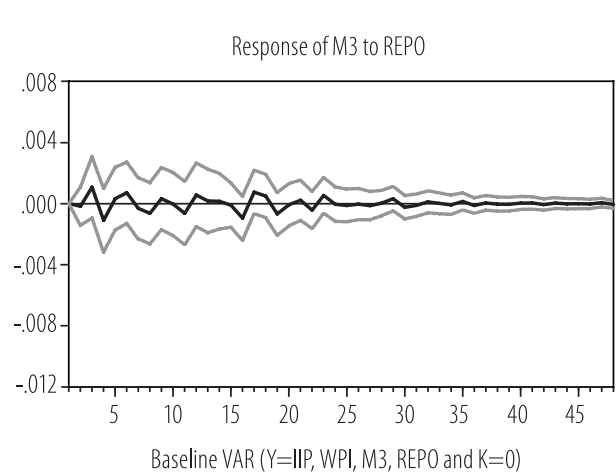

m3

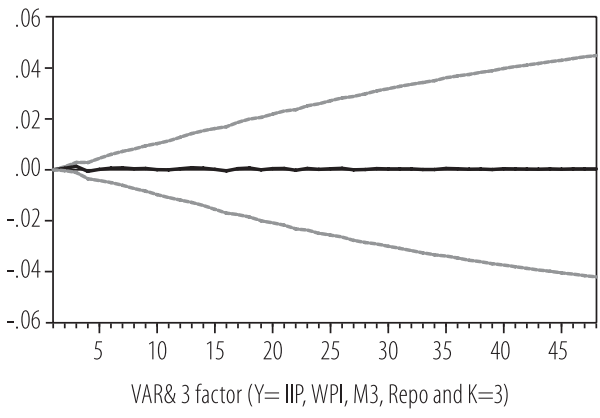

m3

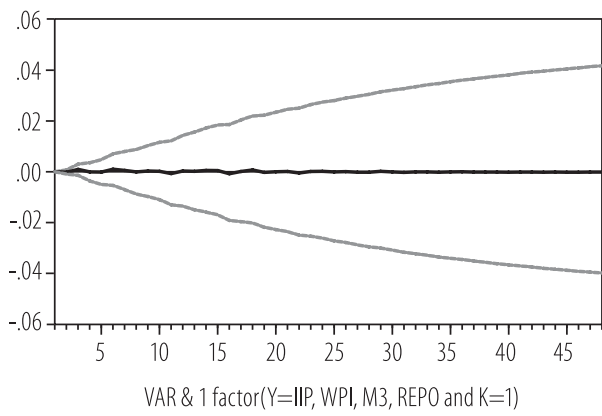

m3

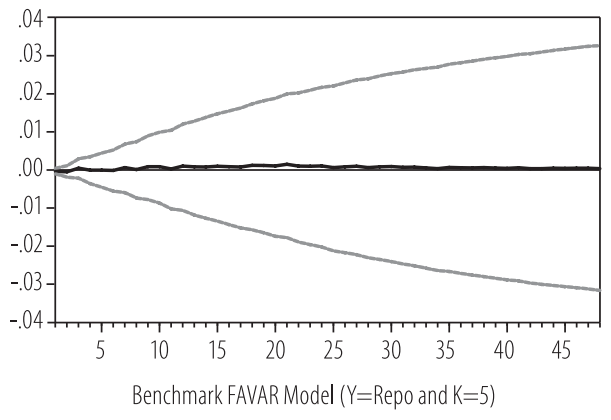

\section{Concluding Remarks}

In this paper, we use a FAVAR model where the factors are estimated using principal component analysis and the parameters of the model with the help of vector autoregression framework to examine the impacts of monetary policy on output, level of inflation, and money. A set of 59 variables was included in the model, covering the period 2001: M4 to 2016: M3. All these variables are used in order to extract the factors. Our evidence shows that the Benchmark FAVAR model performed better than the baseline VAR in all four cases since it provides more reliable results than the baseline VAR model. The benchmark FAVAR model shows the existence of weak liquidity puzzle in India which means that an increase in interest rate causes the money supply to increase. The FAVAR model provides evidence that transmission of monetary policy shocks is faster in case of inflation as compared to output in India. Our results are in tandem with the findings of Bhattacharyya and Sensarma (2005), Ramachandran and Kamaiah (1994) where 
they found that monetary policy is more effective in explaining the variations in inflation rather than stimulating output.

The Reserve Bank of India is in the process of setting Flexible Inflation Targeting. Our empirical findings implicitly recommend the Reserve Bank of India to address the issue of existence of weak liquidity puzzle in formulating policies. Our results indicate that the transmission of monetary policy is faster in case of inflation as compared to that of the output in India which will help the policy makers in the monetary policy formulation. 


\section{References}

1. Aguir, A. (2018). Central Bank Credibility, Independence, and Monetary Policy. Journal of Central Banking Theory and Practice, 7(3), 91-110.

2. Awdeh, A. (2019). Monetary Policy and Economic Growth in Lebanon. Journal of Central Banking Theory and Practice, 8(2), 147-171.

3. Belviso, F., \& Milani, F. (2006). Structural factor-augmented VARs (SFAVARs) and the effects of monetary policy. Topics in Macroeconomics, 6(3).

4. Bernanke, B. S., \& Boivin, J. (2003). Monetary policy in a data-rich environment. Journal of Monetary Economics, 50(3), 525-546.

5. Bernanke, B. S., \& Gertler, M. (2001). Should central banks respond to movements in asset prices? American Economic Review, 91(2), 253-257.

6. Bernanke, B. S., Boivin, J., \& Eliasz, P. (2005). Measuring the effects of monetary policy: A factor-augmented vector autoregressive (FAVAR) approach. Quarterly Journal of Economics, 120(1), 387-422.

7. Bhattacharyya, I., \& Sensarma, R. (2005). Signalling instruments of monetary policy: The Indian experience. Journal of Quantitative Economics, 3(2), 180-196.

8. Bhattacharyya, I., \& Sensarma, R. (2008). How effective are monetary policy signals in India? Journal of Policy Modeling, 30(1), 169-183.

9. Bicchal, M. (2010) Monetary Policy and Inflation in India: A Structural VAR Analysis, 53(3), Available at: http://dx.doi.org/10.2139/ssrn.1813886

10. Boivin, J., \& Giannoni, M. P. (2006). Has monetary policy become more effective? Review of Economics and Statistics, 88(3), 445-462.

11. Figueiredo, F. M. R. (2010). Forecasting Brazilian inflation using a large data set. Central Bank of Brazil Working Paper, 228. Available at: https://www. bcb.gov.br/pec/wps/ingl/wps228.pdf

12. Gambacorta, L., Hofmann, B., \& Peersman, G. (2014). The effectiveness of unconventional monetary policy at the zero lower bound: A cross-country analysis. Journal of Money, Credit and Banking, 46(4), 615-642.

13. Júnior, J. L. R. (2009). Identification of monetary policy shocks and its effects: FAVAR methodology for the Brazilian economy. Brazilian Review of Econometrics, 29(2), 285-313.

14. Kannan, R., Sanyal, S., \& Bhoi, B. B. (2007). Monetary conditions index for India. RBI Occasional Papers, 27, 57-86.

15. Lagana, G., \& Mountford, A. (2005). Measuring Monetary Policy in the UK: A Factor-Augmented Vector Autoregression Model Approach. Manchester School Supplement, 73, 77-98. 
16. Lahura, E. (2010). The effects of monetary policy shocks in Peru: Semistructural identification using a factor-augmented vector autoregressive model. Banco Central de Reserva del Perú, Documento de Trabajo, 8, 1-49.

17. Mordi, C. N., Adebiyi, M. A., Adenuga, A. O., Adebayo, O. M., Abeng, M. O., Akpan, I. N., \& Evbuomwan, O. O. (2013). Modeling the real sector of the Nigerian economy (pp. 1-59). CBN, Research Department.

18. Munir, K., \& Qayyum, A. (2014). Measuring the effects of monetary policy in Pakistan: a factor-augmented vector autoregressive approach. Empirical Economics, 46(3), 843-864.

19. Nachane, D. M., Ray, P., \& Ghosh, S. (2002). Does Monetary Policy Have Differential State-Level Effects? An Empirical Evaluation. Economic and Political Weekly, 37(47), 4723-4728.

20. Primiceri, G. E. (2005). Time varying structural vector autoregressions and monetary policy. Review of Economic Studies, 72(3), 821-852.

21. Qayyum, Abdul (2006). Money, inflation, and growth in Pakistan. Pakistan Development Review, 45(2), 203-212.

22. Rajan, R. S., \& Yanamandra, V. (2015). Effectiveness of Monetary Policy in India: The Interest Rate Pass-Through Channel. In Managing the Macroeconomy (pp. 40-73). Palgrave Macmillan, London.

23. Ramachandran, M., \& Kamaiah, B. (1994). Separability of Monetary Assets: Some Evidence from Approximation Analysis for India. Journal of Quantitative Economics, 10, 337-50.

24. Ramachandran, M., \& Kumar, R. (2017). Shocks and inflation. RBI DRG series, Available at: https://rbidocs.rbi.org.in/rdocs/Publications/PDFs/ DRG30032017B9FD5B290FB94079A6B81A987D02B04A.PDF

25. Rangarajan, A., Talora, C., Okuyama, R., Nicolas, M., Mammucari, C., Oh, H., ... \& Miele, L. (2001). Notch signaling is a direct determinant of keratinocyte growth arrest and entry into differentiation. The EMBO journal, 20(13), 3427-3436.

26. Rangarajan, C. (1997). Role of monetary policy. Economic and Political Weekly, 3325-3328.

27. Reddy, Y. V. (2004). Monetary and financial sector reforms in India: a practitioner's perspective. In K Basu \& C Marks (Eds), India's emerging economy: Performance and prospects in the 1990s and beyond, 61-82.

28. Ribon, S. (2011). The Effect of Monetary Policy on Inflation: A Factor Augmented VAR Approach using disaggregated data (No. 2011.12). Bank of Israel.

29. Roşoiu, A. (2015). Monetary policy and factor-augmented VAR model. Procedia Economics and Finance, 32, 400-407. 
30. Samantaraya, A. (2009). An Index to Assess the Stance of Monetary Policy in India in the Post-Reform Period. Economic and Political Weekly, 44(20), 46-50.

31. Saxegaard, M. (2006). Excess liquidity and the effectiveness of monetary policy: evidence from Sub-Saharan Africa (No. 6-115). International Monetary Fund.

32. Sims, C. A. (1992). Interpreting the macroeconomic time series facts: The effects of monetary policy. European Economic Review, 36(5), 975-1000.

33. Smitha, T. H., \& Sankaranarayanan, K. C. (2010). Impact of monetary policy on indian economy in the post-reform period (Doctoral dissertation, Cochin University of Science \& Technology).

34. Stock, J. H., \& Watson, M. W. (2002). Forecasting using principal components from a large number of predictors. Journal of the American Statistical Association, 97(460), 1167-1179.

35. Twinoburyo, E. N., \& Odhiambo, N. M. (2018). Monetary policy and economic growth: a review of international literature. Journal of Central Banking Theory and Practice, 7(2), 123-137.

36. Upadhyaya, K. P. (1991). The efficacy of monetary and fiscal policies in developing countries: An application of the St. Louis Equation. Indian Economic Journal, 39(1), 35.

37. Vasudevan, A. (2002). Evolving monetary policy in India: some perspectives. Economic and Political Weekly, 37(11), 1055-1061. 


\section{Appendix}

The table is a complete description of the variables and transformation applied to the series to make stationary.

\begin{tabular}{|c|c|c|c|c|}
\hline S. no & VARIABLE & Transformation & $\begin{array}{c}\text { Slow/ } \\
\text { fast }\end{array}$ & Details of Variable \\
\hline \multicolumn{5}{|c|}{ External } \\
\hline 1 & NEER & 3 & Fast & Nominal Effective Exchange Rate(NSA) \\
\hline 2 & REER & 2 & Fast & Real Effective Exchange Rate(NSA) \\
\hline 3 & $\mathrm{FE}$ & 5 & Slow & Foreign Exchange(SA) \\
\hline 4 & SDR & 3 & Slow & Special Drawing Rights(SA) \\
\hline 5 & TR & 3 & Slow & Total Reserves(SA) \\
\hline 6 & M & 3 & Slow & Imports(SA) \\
\hline 7 & $x$ & 3 & Slow & Exports(SA) \\
\hline 8 & OX & 3 & Fast & Oil exports(NSA) \\
\hline 9 & NOX & 3 & Slow & Non-oil exports(SA) \\
\hline 10 & $\mathrm{OM}$ & 3 & Fast & Oil Imports(NSA) \\
\hline 11 & $\mathrm{NOM}$ & 3 & Slow & Non-oil Imports(NSA) \\
\hline \multicolumn{5}{|c|}{ Interest rate } \\
\hline 12 & CMR & 1 & Fast & Call money Rate(NSA) \\
\hline 13 & Y SGL1 & 3 & Fast & Yield of Government Securities 15-91(NSA) \\
\hline 14 & Y SGL3 & 3 & Fast & $\begin{array}{l}\text { Yield of Government Securities } \\
183-364(\text { NSA) }\end{array}$ \\
\hline 15 & Repo & 3 & Fast & Repo(NSA) \\
\hline \multicolumn{5}{|c|}{ Money } \\
\hline 16 & $\mathrm{CC}$ & 3 & Fast & Currency in circulation(SA) \\
\hline 17 & CB & 3 & Fast & Currency with Banks(SA) \\
\hline 18 & $C P$ & 3 & Fast & Currency with public(SA) \\
\hline 19 & OD RBI & 2 & Fast & Other deposits with RBI(SA) \\
\hline 20 & BDRBI & 3 & Fast & Banker's deposit with RBI(SA) \\
\hline 21 & DD & 3 & Fast & Demand Deposit(SA) \\
\hline 22 & TD & 3 & Fast & Time Deposit(SA) \\
\hline 23 & MO & 3 & Fast & Reserve Money(SA) \\
\hline 24 & M1 & 5 & Fast & Narrow Money(SA) \\
\hline 25 & M3 & 5 & Fast & Broad Money(SA) \\
\hline \multicolumn{5}{|c|}{ Stock prices } \\
\hline 26 & ER BSE & 3 & Fast & Earnings Ratio of BSE(NSA) \\
\hline 27 & BVR BSE & 3 & Fast & Book Value Ratio of BSE(NSA) \\
\hline
\end{tabular}




\begin{tabular}{|c|c|c|c|c|}
\hline 28 & MC BSE & 3 & Fast & Market Capitalisation- BSE(SA) \\
\hline 29 & MC NSE & 3 & Fast & Market Capitalisation- NSE(SA) \\
\hline 30 & MT BSE & 3 & Fast & Monthly Turnover BSE(SA) \\
\hline 31 & MT NSE & 3 & Fast & Monthly Turnover NSE(SA) \\
\hline 32 & NIFTY & 3 & Fast & Annual Averages of S\&P CNX Nifty(NSA) \\
\hline \multicolumn{5}{|c|}{ Output } \\
\hline 33 & $\| P$ & 3 & Slow & Index of Industrial Production(SA) \\
\hline 34 & IIP BG & 5 & Slow & IIP-Basic Goods(SA) \\
\hline 35 & $\| P C G$ & 5 & Slow & IIP-Capital Goods(SA) \\
\hline 36 & $\| P I G$ & 3 & Slow & IIP- Intermediate Goods(SA) \\
\hline 37 & IIP CND & 3 & Slow & IIP-Consumer Non-durables(SA) \\
\hline 38 & IIP ELE & 3 & Slow & IIP-Electricity \\
\hline 39 & IIPM & 3 & Slow & IIP- Minerals \\
\hline 40 & IIP MQ & 3 & Slow & IIP- Mining and Quarrying \\
\hline 41 & IIP CNG & 5 & Slow & IIP-Consumer Goods \\
\hline \multicolumn{5}{|c|}{ Prices } \\
\hline 42 & $C P I A G$ & 5 & Slow & CPI- Agriculture(SA) \\
\hline 43 & $\mathrm{CPI} R \mathrm{~L}$ & 5 & Slow & CPI- Rural Labour(SA) \\
\hline 44 & WPI & 3 & Slow & Wholesale Price Index(SA) \\
\hline 45 & WPI PA & 3 & Slow & WPI-Primary Articles(SA) \\
\hline 46 & WPI FA & 3 & Slow & WPI-Food Articles(SA) \\
\hline 47 & WPI TEX & 3 & Slow & WPI- Textiles(SA) \\
\hline 48 & WPIE & 3 & Slow & WPI- Electricity(SA) \\
\hline 49 & WPI MP & 3 & Slow & WPI- Manufacturing(SA) \\
\hline 50 & WPI BM & 3 & Slow & WPI- Basic Metals(SA) \\
\hline 51 & WPI BV & 3 & Slow & WPI- Beverages and Tobacco(SA) \\
\hline 52 & WPI FP & 3 & Slow & WPI- Fuel and Power \\
\hline 53 & WPI LP & 3 & Slow & WPI-Leather Products \\
\hline 54 & WPI M & 3 & Slow & WPI- Minerals \\
\hline 55 & WPI NFA & 3 & Slow & WPI- Non-food Articles \\
\hline 56 & WPI PLP & 3 & Slow & WPI- Plastic Products \\
\hline 57 & WPI PP & 5 & Slow & WPI- Paper Products \\
\hline 58 & WPI TE & 3 & Slow & WPI-Transport Equipment \\
\hline 59 & WPI WP & 3 & Slow & WPI- Wood Products \\
\hline
\end{tabular}

Transformation codes are: 1 No transformation, 2 Log transformation, 3 First difference, 4 First difference of log and 5 second difference, SA seasonally adjusted, NSA not seasonally adjusted 